\title{
Analysis of methods for assessing the drilling tool performance
}

\author{
Denis Simisinov * ${ }^{*}$ Konstantin Porozhkiy, Olga Pozdnyakova, and Ivan Zakharov \\ Ural State Mining University, 620144, Ekaterinburg, Russia
}

\begin{abstract}
The analysis of methods for assessing the drilling tool performance using various methods was performed. The applicability of the methods was assessed. Methods based on periodic comparative tests were examined in detail. The technical level and operational efficiency of the drilling tool is determined by the resource (tool driftage), drilling speed, durability, power supplied to the bottom of the well. The correct choice of a drilling tool is ultimately determined by economic assessments. The specific drilling costs are proposed to be determined taking into account the cost of one machine hour, the sharpening of crowns and the average mechanical drilling speed.
\end{abstract}

In the mining industry, drilling rock cutting tools are used for drilling: drill bits and crowns of various purposes, designs, materials and sizes. In addition, the tool of one purpose and size is distinguished by quality and price, which depend on the level of technology of the manufacturer, its integrity and pricing policy of manufacturers (suppliers).

The use of a drilling tool in a particular enterprise-consumer should be accompanied by its effectiveness assessment.

Various performance criteria are used to evaluate and select more advanced or new drilling tool models.

The technical level and operational efficiency of the drilling tool is determined by the resource (tool driftage), drilling speed, durability, power supplied to the bottom of the well. Economic efficiency is expressed by the ratio between the effect and the costs, which are formed by such factors as purchase costs, resource, operating costs.

The correctness of the choice of a drilling tool is finally determined by economic assessments that take into account the type and parameters of drilling equipment, as well as the technical and economic conditions for drilling and blasting operations, developed on a specific example.

The drilling tool performance can be assessed by various methods:

1)according to the results of periodic (installation, acceptance, comparative) tests under a specific technique;

2)according to the information of the drilling log;

3)according to the results of accelerated tests (bench tests), technical diagnostics or examination;

\footnotetext{
*Corresponding author: 7sinov@mail.ru
} 
4)by conducting laboratory studies of the physical and mechanical properties of drilling tool materials.

Periodic tests are the most reliable, but time-consuming method, which requires the involvement of resources involved in the main technological process of the enterprise.

Information on the process and results of drilling tool operation from the drilling log has limitations on the recorded characteristics. Tool development results are not comparable due to different operating conditions of the drilling tool.

The use of assessment methods based on the study of the drilling process of rocks directly in the production environment to obtain reliable results, involves significant costs of time and money. Accelerated tests allow to obtain quickly reliable information with minimal labor, but require testing equipment and personnel availability and generally lead to wasteful expenditures.

The method of studying the physical and mechanical properties of products is widely used in quality control of products in mechanical engineering. This method will be effective in a comparative analysis of the properties of the metal in case when the performance of the prototypes during comparative tests are significantly different from the results of the operation of a batch of tools (equipment). This can be caused by a violation of the manufacturing technology of the experimental batch, the use of low-quality metal, etc. The method allows you to assess the properties of the sample metal and to show the reasons for the discrepancies in the samples' performance. This can serve as a basis for justifying failures in the supply of a batch of substandard equipment (tools) without additional comparative tests

A generalized description of the available methods for drilling tool performance assessment is given in table 1 .

Table 1. Methods for assessing the drilling tool (DT) performance

\begin{tabular}{|c|c|c|}
\hline Method & Advantages & Disadvantages \\
\hline $\begin{array}{l}\text { Comparative } \\
\text { tests }\end{array}$ & $\begin{array}{l}\text { The conditions are as close } \\
\text { as possible to operational ones }\end{array}$ & \begin{tabular}{|l} 
Limited number of tests. \\
Reproduction inaccuracy of test \\
conditions
\end{tabular} \\
\hline Drilling Log & $\begin{array}{l}\text { Actual operating conditions. } \\
\text { Minimum costs (conditionally) }\end{array}$ & $\begin{array}{l}\text { Anonymity of the T operation results. } \\
\text { It is difficult to organize the accounting } \\
\text { of the number of DT re-sharpening. }\end{array}$ \\
\hline Bench tests & $\begin{array}{ccc}\begin{array}{c}\text { Close } \\
\text { conditions }\end{array} & \text { to operational }\end{array}$ & $\begin{array}{l}\text { Cost on stand creation and its } \\
\text { maintenance. Complicated by the need to } \\
\text { ensure testing of the entire DT nomenclature }\end{array}$ \\
\hline 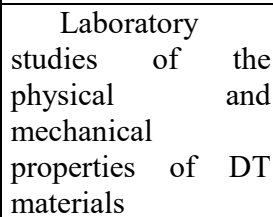 & $\begin{array}{l}\text { Slight time expenses spent } \\
\text { on testing. High reliability. } \\
\text { Universality. Possibility to } \\
\text { establish the causes of failures } \\
\text { and to identify defects }\end{array}$ & $\begin{array}{l}\text { Expenses on equipping the laboratory } \\
\text { and its work. Lack of reliable data on the } \\
\text { relationship of quality indicators of } \\
\text { materials and the DT resource }\end{array}$ \\
\hline
\end{tabular}

To assess the operability and performance of the drilling tool in a particular enterprise, various methods of comparative pilot industrial testing of the drilling tool are proposed. They consider not only technical performance (driftage in meters, resistance in hours), but also the costs.

The methodology developed by Bogoslovskoye Mine Management OJSC and the Mining Institute of the Ural Branch of the Russian Academy of Sciences [1] implies the use of the following drilling tool performance indicators: number of units of the drilling tool used, unit cost, total cost of the drilling tool used, drilling volume, wear resistance. According to the developers, these indicators can be used to plan the needs of a mining enterprise for a drilling 
tool, control its consumption, standardize its flow rate and select the most suitable supplier, and plan and forecast drilling costs.

It is proposed to process the obtained quantitative test results according to the method [1] with the required degree of accuracy to obtain reliable data, excluding deviations of a clearly random nature. To do this, according to experimental data, charts are built. The abscissa of the chart is the resistance of the crown (bar) in meters, the ordinate is the strength of the rock; accordingly, the durability of each type of crown during each particular test will be represented by a dot on the chart. The connection of the points forms a certain broken line characterizing the empirical dependence of crown resistance on mining-egineering conditions. Further, a line (curve or straight) is selected that best fits into this polygonal line and represents the correlation dependence of crown resistance on mining engineering conditions. Then the standard form of the equation is selected that most satisfactorily describes the relationship being studied. This equation is an analytical dependence of crown resistance on mining engineering conditions. The coefficients of the equation are determined by the least squares method. It is assumed that the analytical dependence obtained from experimental data is the main predictive tool for determining the drilling tool flow rate, substantiating flow rates and planning the need for a particular mining enterprise.

In the paper [2], it was proposed to determine the cost savings for drilling tools, obtained as a result of each measure to increase the efficiency of the drilling tool, according to the following formula:

$$
\Delta C=\frac{A}{d_{2}} S_{1}+\frac{A}{d_{2}} S_{2}
$$

where $S_{1}$ and $S_{2}$ are the prices for drilling tools respectively, regular and new, rubles. pc.;

A - penetration volume, $\mathrm{m}$;

$d_{1}$ и $d_{2}$ - number of units of the drilling tool after and before the event, pcs.

The technique of operability and efficiency of the drilling tool under the conditions of Kazzinc LLP is integrated into the comprehensive program and test method for perforators, pneumatic impact tools and drilling tools [3]. The methodology describes the procedure for calculating the consumption rates of drill drowns for mining operations (in units per $1000 \mathrm{~m}^{3}$ of mining):

1) The average durability of the drill bits in each face $(\mathrm{m})$ is determined:

$$
T_{n}=L: n
$$

where L - total metreage drilled with tested crowns, taken into account, $m ; n$ - number of tested crowns, pcs.

2) The average durability of drill bits for the group of faces $(m)$ is calculated:

$$
T=\frac{T_{1}+T_{2}+\cdots+T_{n}}{m}
$$

where $T_{1}, T_{2}, \ldots, T_{n}$ - average values of the drill crowns resistance on the faces with the same mining and geological conditions, $\mathrm{m}$.; $m$ - number of faces.

3) The weighted average value of the output of the rock mass from $11 \mathrm{~m}$. of drill hole in the group of faces is determined:

$$
P=\frac{P_{1} a_{1}+P_{2} a_{2}+\cdots+P_{m} a_{m}}{100}
$$

where $P_{1}, P_{2}, \ldots, P_{m}$ - output of the rock mass with 11 .m. of drill hole for workings of a certain combination, $\mathrm{m}^{3} / \mathrm{m}$ (in accordance with the actual measurement);

$a_{1}, a_{2}, \ldots, a_{m}-$ corresponding percentage of workings of the same section. 
4) The consumption rate of drill crowns for the group of faces for $1000 \mathrm{~m}^{3}$ of mining $\left(\mathrm{pcs} / \mathrm{m}^{3}\right)$ is calculated:

$$
N=\frac{1}{T P} 1000
$$

The same methodology proposes a similar procedure for calculating the consumption rates of drill crowns for second working.

The technique proposed [4] consists of four stages:

1) preparatory: registration in the test report of initial data on the location, date of testing, drilling conditions and technical characteristics of the equipment set, initial technical and economic parameters for calculating the cost of direct expenses for drilling $1 \mathrm{~m}$ of wells;

2) registration: registration of the axial movement of the column with the simultaneous recording of acoustic signals that occur during the operation of the pneumatic impact tool during the drilling of wells at set drilling modes, which are recorded by monitoring devices of drilling rigs or autonomous measuring devices;

3) measuring and calculating: processing the data of measuring equipment and determining the technical and technical-economic parameters obtained in the process of wells drilling with recording in the energy efficiency certificate of submersible machines;

4) reporting and analytical: building diagrams for assessing energy efficiency of drilling wells, drawing up reporting documentation with recommendations for selecting and adapting a specific model of a submersible pneumatic impact tool and rock cutting tool with the provision of rational drilling parameters and recommendations for cleaning the well from sludge and timely sharpening of rock cutting inserts of drill bits.

As the main criterion, the energy criterion the volumetric destruction energy criterion $\mathrm{k}$ and the criterial energy index $\mathrm{k}_{\mathrm{c}}$ are recommended.

$$
k=k_{c} \eta=\left(\frac{E_{c}(t) \alpha}{V_{\rho}(t) \rho v_{\rho}^{2}}\right) \eta=(1 \div 4) \cdot 10^{-9}
$$

where $k_{c}$ - criterial energy index; $E_{\mathrm{c}}(t)$ - air energy supplied to the drill string, $\mathrm{J} ; \alpha$ coefficient of pulsed rock-destructing effect of the tool on the rock mass $\left(\alpha \cdot 10^{-6}\right) ; V_{\rho}(t)$ volume of the destroyed rock during the passage of the control section of the drilled well run, $\mathrm{m}^{3} ; \rho$ - density of the rock mass of the deposit (drilling site) $\mathrm{kg} / \mathrm{m}^{3} ; v_{\rho}$ - velocity of the longitudinal wave in the rock mass; $\eta$ - efficiency factor of the pneumatic impact tool.

It was proposed to consider issues of increasing the productivity of pneumatic impact drilling from the standpoint of energy efficiency of drilling operations [4]. For express evaluation of the energy efficiency of drilling with submersible pneumatic impact tools, it is advisable to use the volumetric destruction energy criterion $k$ and the criterial energy index $k_{c}$. In contrast to assessing energy efficiency by the cost of direct expenses for wells drilling $C$, the determination of $k_{c}$ and $k$ indicators takes less time and does not require economic data, but correlates with them (in terms of energy consumption). In addition, the indicators $k_{c}$ and $k$ contain the physical and mechanical properties of drilled rocks and, in contrast to the $C$ indicator, they allow accurate and reliable assessment of energy efficiency of drilling operations at any time interval.

The $k_{c}$ indicator allows, without data on the efficiency factor of pneumatic impact tools, to reliably determine the machine model that has the maximum productivity with minimum energy consumption of energy carriers, and, accordingly, provides the lowest cost of direct expenses for wells drilling in specific mining and geological conditions.

The use of techniques for assessing the drilling tool performance and efficiency by conducting comparative pilot industrial tests exposes many problems that stand in the way of increasing the efficiency of rotary shock drilling. 
The main problems, as drilling experience shows, are related to the quality of the drilling tool and insufficiently effective monitoring of its operation.

The above methods are not used in enterprises due to the difficulty of organizing the accounting of the conditions and results of the drilling tool in production conditions, the difficulties in assessing the correlation of the tool life from rock strength and other mining and technical conditions that have a significant dispersion within the mine workings.

A.I. Spivak and A.N. Popov [6] consider the cost of $1 \mathrm{~m}$ of driftage as the most common integral indicator of the work of the bit. However, due to the complexity of determining this indicator, it is recommended to use a cost indicator of $1 \mathrm{~m}$ of driftage by time-dependent costs, and calculated by the following formula:

$$
S=\frac{\left(T+T_{t}\right) C_{h}+C_{t}}{H}
$$

where $C_{h}$ - cost of operating the drilling rig for 1 hour; $C_{t}$ - cost of the drilling tool; $T_{t}$ time for auxiliary operations attributed to the well; $H$ - bit driftage.

The methodology proposed by the authors of the article determines the objects, location, conditions and test procedure, measurement methods, criteria for assessing the results and recommendations for the selection of effective drilling tool. The main principle of the developed methodology is the compliance with the same types of approaches and test conditions that ensure objectivity and accuracy in performance and effectiveness assessment of the tested drilling tool in order to objectively identify the best technical samples of drilling equipment and tools, providing increased productivity and reduced drilling costs.

A distinctive feature of the technique is that during drill crowns testing it is proposed to take into account the sharpening of the crowns.

The test results of drilling tools samples in the same conditions for the reporting period are recorded in the register of performance indicators of drilling equipment and tools. Comparison of the efficiency of the drilling tool is carried out according to a number of indicators: average mechanical drilling speed, average driftage taking into account the standard deviation, average durability and unit cost of drilling (drilling tool).

Unit drilling costs, i.e. the cost of a drilling tool when drilling $1 \mathrm{~m}$ of drill hole (well), rubles $/ \mathrm{m}$, are determined by the total drilling tool performance obtained during testing, according to the following formula:

$$
C_{\text {и }}=\frac{n_{s} \mathrm{C}_{\mathrm{s}}+n_{\mathrm{b}} \mathrm{C}_{\mathrm{b}}}{L}
$$

Where:

$n_{\mathrm{s}}$ - total number of sharpening operations;

$C_{s}-$ cost of 1 sharpening of the crown;

$n_{b}$ - number of spent samples of the drilling tool, units;

$C_{b}-$ cost per unit of the drilling tool;

$L$ - total driftage, $\mathrm{m}$.

If necessary, the unit costs of drilling can be calculated taking into account the cost of one machine hour and the average mechanical drilling speed (provided they are accurately determined). In this case, the corresponding term and drilling unit costs are added to formula (8), calculated as follows:

$$
\mathrm{C}_{\sigma}=\frac{C_{t}}{V_{d}}+\frac{n_{s} \mathrm{C}_{\mathrm{s}}+n_{\mathrm{b}} \mathrm{C}_{\mathrm{b}}}{L}
$$

where $V_{d}$-average mechanical drilling speed, $\mathrm{m} / \mathrm{h} ; C_{t}-$ cost of 1 machine hour of drilling. 
Moreover, to exclude the influence of random factors on drilling performance, the values of $V_{d}$ and $C_{t}$ should be determined taking into account the net drilling time, excluding auxiliary operations.

With a difference in the methods for assessing the operability and efficiency of the drilling tool, all of them, with proper practical application, contribute to improving the technical and economic performance of mining enterprises, including increase of labor productivity, production profitability by reducing drilling costs.

\section{References}

1. R. I. Sukhov, Research Report Development of a methodology for conducting comparative industrial tests of drilling tools of domestic and foreign production at mining enterprises of the UMMCcity of Yekaterinburg, 63 (2006)

2. A. S. Regotunov, R. I. Sukhov, E3S Web of Conferences, 1002 (2018)

3. F. Dunaev, V. A. Shpakov, N.P. Epifanova, V. N. Lyndin, Economy of oil and gas industry enterprises, 352 (2006)

4. The program and methodology for testing perforators, hammers and drilling tools, Kazzinc LLP. City of Oskemen, 9 (2014)

5. V. N. Karpov, Fundamental and applied issues of mining sciences, 2(3), 74 (2016)

6. A. N. Popov, A. I. Spivak, T. O. Akbulatov, Oil and gas well drilling technology, 509 (2003) 